\title{
Employment and working conditions and the supply chain for commodities in retail - a case study of rice in Chennai.
}

\section{Mohan Mani, Gautam Mody and Meghna Sukumar ${ }^{1}$}

\author{
November, 2013 \\ Working Paper no 11 \\ http://www.southasia.ox.ac.uk/resources-greenhouse-gases-technology-and-jobs-indias- \\ informal-economy-case-rice
}

\section{Background}

The research on labour reported here seeks critically to examine questions of employment practices and working conditions at the retail stage of the supply chains for rice. It is an exploratory component of larger research on the supplychain. ${ }^{2}$ While WP 16 analyses upstream logistics, costs and profits and labour arrangements, here we focus on the retailing of rice in and around Chennai, seeking to understand retail business in a sector that continues to be primarily dominated by small firms and informal relations of employment. Apart from its exploratory purpose, this work is also driven by a policy question: whether fresh investment in the sector, in particular the entry of large corporate interests in

\footnotetext{
${ }^{1} \mathrm{MM}$ and MS: Centre for Workers' Management; GM: New Trade Union Initiative

${ }^{2}$ See WP 16. Its relevance to the even larger project on greenhouse gases and livelihoods of which it is a component is that a low $C$ transition would necessarily involve new scales of capital and create new kinds of employment. The potential of improving the quality as well as quantity of formal jobs is therefore tested here against existing trends in new scales of capital and in the conditions of work amid the formalising of a hitherto informal sector - that of retail.
} 
retail, changes employment practices - and if so, then how? Existing literature suggest many possibilities.

First, previous research on labour relations has suggested a clear-cut difference between situations of employment in the formal and informal sectors - these being defined by different ownership patterns with different legal regimes governing their existence. ${ }^{3}$ Large business interests were seen to operate in the formal sector, with requirements of strict legal compliance in all aspects of business including employment relationships. In the $21^{\text {st }}$ century, with the growth of new labour practices, including the spread of contract employment and outsourced work, the clear conceptual differences between the formal and informal sectors may not exist in the workplace, especially where labour relations are concerned. ${ }^{4}$ We see growing informality in the formal sector. Consequently, the retail sector is of particular interest, given this is a sector sited primarily in the informal economy that is opening up to corporate business interests. Will this lead to changes in the sector's workforce and employment relations?

Second, modern urban retail is seen as a sector employing women in large numbers. In the past, women in metro cities have been entering the labour market at the lower end of formal employment. The garment industry is a case in point, with factory based garment work employing an estimated two hundred

\footnotetext{
${ }^{3}$ See Fields, Gary S., 1975, "Rural-urban migration, urban unemployment and underemployment and job search activity in LDCs," Journal of Development Economics, Vol.2, No.1, June, pp.165-187 and Mazumdar, Dipak, 1975, "The Theory of Urban Unemployment in Less Developed Countries," World Bank Staff Working Paper, No.198.
}

${ }^{4}$ See for instance Dan Gallin, (2001), "Propositions on Trade Unions and Informal Organisation in times of Globalisation", Blackwell Publishers, Oxford; and Martha Alter Chen, 2004, "Rethinking the Informal Economy: Linkages with the Formal Economy and Formal Regulatory Environment", paper submitted at the EGDI-WIDER Conference on "Unleashing Human Potential: Linking the Informal and Formal Sectors", Helsinki, Finland. 
thousand workers in the city of Chennai, the large majority of them being women. ${ }^{5}$ While employment in the sector is formally covered by labour legislation that guarantees tenure of employment and rights of minimum wages, regulated hours of work and social security, in reality workers are found without any of these rights. Employers understand that the feminisation of labour enables them to reduce compliance with the formal regulation of employment relations. Feminisation of labour also enables employers to keep wages low. ${ }^{6}$ This is another aspect of retail industry that needs to be studied and understood.

Third, retail commodity trade is the final end of a supply chain linking rural production to urban consumption. The labour relations within the system are also a matter of interest. What are the major links in this production and procurement chain? What is the nature of the business interests pervading this system? How will they also be affected by entry of big business? These questions are of particular interest today in India because retail trade and government regulation are matters of immediate political contestation. ${ }^{7}$

The present research seeks to explore these questions through a field study of the rice supply chain covering aspects of employment practices and working conditions in different retail employment categories. The paper is divided into two sections, the first dealing with the terms and conditions of employment in big and small retail sectors and the second discussing some of the answers we can draw from this study to the questions we have proposed.

\footnotetext{
${ }^{5}$ Estimates of the Garment and Fashion Workers Union, Tamil Nadu.

${ }^{6}$ Chen, Martha, Vanek, J and Heintz, J. (2006), "Informality,Gender and Poverty: A Global Picture", Economic and Political Weekly, Vol. XLI, No. 21.

${ }^{7}$ While the research reported here has tried to touch on some aspects of the procurement chain, this has not been its main focus.
} 


\section{Employment and working conditions in retail}

\section{Field Methodology}

\section{Questionnaire:}

A questionnaire (a checklist of questions) was developed for administration to workers in retail shops. It was discussed with other members of the study team, ${ }^{8}$ then pilot-tested for ease of understanding and relevance, before finalisation. The principal researcher conducted the preliminary set of interviews along with the other members of the research team (all union activists in the informal sector, with some knowledge of English) to ensure a common approach to asking questions and reporting the discussion. The involvement of union activists in this field research served two purposes. First it ensured researcher empathy, as the researchers came from the same social and economic background as the retail employees being researched. Second, it satisfied an important capacity-building objective of the main research project: to enable women activists in the informal sector to gain first-hand experience of conducting surveys and doing basic research. We were less successful in obtaining responses on quantities, costs and prices from employers despite these interviews being carried by the principal researcher. There was significant

\footnotetext{
${ }^{8}$ Research Team: The interviews were carried out by a team comprising Kavitha and Josephine. Kavitha, the primary interviewer and Josephine, who assisted in making initial contacts and conducting interviews, have been lifetime residents of Ambattur. They are both college graduates, with Tamil as their primary language of communication, and a working knowledge of English. Both have been volunteering with Penn Thozhilalargal Sangam (Women Workers' Union) an all-women union representing informal sector workers in Chennai, for the last 2-3 years. They are generally well acquainted with the local union activists in the area and the area itself. They were assisted by other union activists of Penn Thozhilalargal Sangam from different localities in Ambattur, the site of our field research.
} 
resistance to answering economic questions even when the academic nature of the research and confidentiality were stressed.

\section{Study location:}

The field-study of employment practices was conducted in Ambattur and Anna Nagar in Chennai. We chose Ambattur, a location about $15 \mathrm{kms}$ to the west of the city centre as it is an old industrial belt of the city familiar to the researchers. ${ }^{9}$ Several small- and medium-scale industries in the Ambattur Industrial Estate are located there alongside larger factories like TI Cycles, Tube India and Dunlop. Several of the small scale industrial units are being closed down and converted into IT parks causing real estate values and rents to go up. The area has a population of around 478,000 as per the 2011 provisional census data. Ambattur used to be a Municipality until a year ago. It is now for all practical purposes a part of the extended Chennai Corporation. While our focus was on Ambattur, we also conducted a few interviews in Anna Nagar where large supermarkets and some of the other smaller stores are located. Anna Nagar is a more middle /upper middle class locality.

\section{Market structure and interview sites:}

We interviewed 37 retail and wholesale workers during the months September 2012-October 2012 and January - February2013. They included ten who work in large supermarket chains and nine in medium size local supermarkets and departmental stores. Fourteen workers were employed in small retail shops and

\footnotetext{
${ }^{9}$ The study area was chosen for the following reasons: i) a cross section of all economic classes live in the region; ii) the region has small neighbourhood shops as well as bigger retailers; iii) the Penn Thozhilalargal Sangam has strong presence in this area. This helped create interviewed workers' trust in the study and therefore ensured the veracity of information collected during interviews.
} 
wholesale shops. Four workers were employed by a Fair Price Shop ${ }^{10}$ in Ambattur. ${ }^{11}$

The categorisation of retail outlets into large, medium and small was based on the form of ownership, the activity mix as well as the scale of the establishment. The big supermarkets are corporate enterprises with multiple branches, extending across the city and even to other cities. The medium size enterprises are large multi-product stores, with walk-in selection of goods- but they are stand-alone establishments, with at most 2-3 branches. The small retail shops deal with customers across the counter, with a more limited product range.

To give a sense of the absolute size and functional complexity of operations of the three categories of stores: the Tata Group owned Trent Hypermarket which owns the Star Bazaar chain of mega supermarkets, for the accounting year 2012-13, had 15 supermarkets across the country, and a combined turnover of Rs.785.91 crores (7,859 million) for the year, or on the average around Rs.50 crores per supermarket. ${ }^{12}$ The manager at one of the Star Bazaar Supermarkets estimated turnover from rice alone as less than $5 \%$ of total turnover, or around Rs. 2 crores per Star Bazaar supermarket. The manager also gave the monthly turnover from a Star Bazaar supermarket of all varieties of rice as around 20MT, or around $240 \mathrm{MT}$ in a year. This works out with a sales purchase of Rs.45 per kg as a little over Rs.1 crore per annum from a supermarket. We can estimate typical rice sales from a large supermarket as in the range of Rs.1-2 crores per year. From our interviews with the manager of a medium sized store, it had an annual turnover of around Rs. 2 crores (estimated for 280 days sale),

\footnotetext{
${ }^{10}$ Fair Price Shops are retail shops that distribute grains and commodity under the Government run Public Distribution System (PDS). In Tamil Nadu the PDS is carried out through 33222 Fair Price Shops, governed by the Tamil Nadu Civil Supplies Corporation, and Cooperatives (www.tncsc.tn.gov.in/html/pds.htm).

${ }^{11}$ Though this could not be a random sample it is illustrative of the relations and processes we wish to study. While generalisations about magnitudes cannot be made from this sample, the cases can be used to illustrate higher order statements about processes.

${ }^{12} 61^{\text {st }}$ Annual Report 2012-13, Trent limited, A Tata Enterprise, www.mywestside.com. Trent Hypermarket, a wholly owned subsidiary of Trent Limited, a Tata enterprise reported an annual turnover for 2012-13 of Rs. 785.19 crores, and a loss before tax of Rs. 76.10 crores.
} 
and rice contributed to $15 \%$ of total turnover, or around Rs.30 lakhs. The owner of a small neighbour store estimated monthly sales as Rs.3 lakhs $(300,000)$, or annual sales of Rs.36 lakhs, of which $20 \%$ of sales are rice. The rice sales from the small store was therefore estimated at around Rs.7 lakhs per annum.

The above estimates are useful as indicators of market structure. While the total annual turnover of the large supermarket is around 25 times that of the neighbourhood medium size supermarket, and over a hundred times that of the small store, in terms of sale of rice alone the multiple is much less. The turnover in the large supermarket is only around 3-4 times that in the medium size supermarket, and around 15-20 times that of the small store for rice alone. A large supermarket therefore replaces only twenty small stores for rice and other staples.

\section{Interview Process:}

Despite the field research team's social rapport, it proved not at all easy to interview workers. ${ }^{13}$ Most of the interviews at the big and medium size retail stores were conducted outside the store during breaks or after work hours especially when the manager or supervisor was away; or at the workers' homes. ${ }^{14}$ In the large supermarkets, many of the experienced workers refused to

\footnotetext{
${ }^{13}$ The interview schedule was pilot tested with one worker from each of the categories - i.e small, medium and big retail. These interviews were jointly conducted by Meghna and Kavitha, and changes in the interview schedule were made based on the interviews. To ensure that all details were obtained, repeat visits were made with each interviewee. Every 2-3 days the team met to consolidate the data and check for omissions or additional clarifications required. In the case of interviews with the big retail stores, many attempts were made to get copy of employment contracts, but workers were too afraid to give copies or claimed that they did not have them. While giving consent to be interviewed, no worker wanted their names to be revealed in any publication.
}

\footnotetext{
${ }^{14}$ Initial contact with retail workers was made through the Penn ThozhilalargalSangam. The benefit of this was an opportunity to build trust with the workers and get accurate information, dispelling any fear of adverse consequences by ensuring that anonymity would be maintained. Many retail workers were prepared and able to give contact of other co-workers. For workers in the ration shops
} 
talk, but no such difficulty arose in interviewing workers from the smaller stores. Curiously workers at the Fair Price Shop also refused to be interviewed as they suspected that the interviewers formed part of a vigilance process. They only agreed to being interviewed at the intervention of their local trade union leader.

\section{The social background of retail workers}

Our purpose in probing social backgrounds was to discover whether new scales of capital and organisation of retail had involved new kinds of workers.

\section{Gender and age:}

Both our experience and the existing literature ${ }^{15}$ tell us that the workforce in small retail is primarily male, often with a kinship relationship with the employer. However in both medium and large retail, workers are significantly younger and largely female.

Of the 19 workers in the sample employed in the big and medium sized retail stores, seven were 20 years or below, and another eight were in the age group 20-25 years, with four above 25 years of age. Seventeen of them were women. Only two workers were men. Discussions with the workers revealed that this was the norm for employee profile in the new retail sector-primarily women, and a young workforce.

of the Government run cooperatives (PDS), contact with workers was established through the General Secretary of Labour Progressive Front, the largest among unions representing workers in the Tamil Nadu Civil Supplies Department.

${ }^{15}$ Harriss-White B 1996 A political economy of agricultural markets in South India: Masters of the Countryside, New Delhi, Sage; 2008 Rural Commercial Capital: Agricultural Markets in West Bengal, New Delhi Oxford University Press 
Many of the women sought employment in retail stores because they were close to home and required minimum travel ${ }^{16}$. Four of the workers had been forced to discontinue school, or college midway, because financial problems in the family (death of father/ breadwinner of the family) had forced them to find work. Many saw retail work as a temporary form of employment ${ }^{17}$. It was difficult to find women workers in retail stores who had more than 2-3 years' experience. Older women were typically employed in packing work and not directly in sales in the retail area. The oldest worker in the sample was 56 years old, employed in a packing section, and earned only Rs.3400 per month which was significantly lower than wages in all three levels of retail work in the shop. In the case of medium size stores we found that older women usually sat in a separate room or outside the shop on the pavement to carry out packing activity. This indicates a progressive degradation of tasks performed by women workers.

In the small retail stores, as expected, men were clearly preferred by shop owners. All fourteen workers in the sample were men. Six of them were 25 years and below, and three were in the age group of 25 to 30 years. Employers also recruited from among relatives/ family acquaintances, very often from the home town of the owner. Eight of the 14 workers in the sample were migrants from Tuticorin district (528 kms by road from Chennai) and distant relatives or known to someone from the same village as the store owner. These employees were very dependent upon their employer. Most of the young men belonged to families who owned small pieces of land, and whose families were involved in agriculture and/or agricultural labour. They move to Chennai and sought

\footnotetext{
${ }^{16}$ This is contributed at least in part by the insecurity of women travelling after hours.

${ }^{17}$ Discussions with union activists at Penn Thozhilalargal Sangam and Garments and Fashion Workers Union (union representing garment workers in Chennai) pointed to a similar employee profile among the workforce in the garments sector. The activists discussed how women garment workers also often saw their employment in the sector as temporary and stop-gap, but ended up in the industry for years.
} 
employment to supplement family income, and gain experience- possibly to open their own retail store. In contrast to the women in bigger stores, they did not regard the work as temporary. Many, however, saw it as a stepping stone to their bettering their future and owning their own small store.

So the entry of bigger scales of retail capital is accompanied by a feminisation of wage work.

\section{Educational qualification and recruitment:}

In small stores, workers commonly lack formal education, but this is substituted for by apprenticeships in retail skills in the store itself. By contrast, in large retail, there is a minimum level of formal education among workers.

Only three workers out of the total sample of $37 \mathrm{had}$ a college education. They were employed in the Fair Price Shop. One male worker had discontinued studies for an ITI (technical diploma) qualification and joined work in a large supermarket with the intention of later starting his own retail store. Two women in large retail stores were enrolled in higher education correspondence courses while working. Most other large retail workers had finished their $10^{\text {th }}$ or $12^{\text {th }}$ standard schooling before starting work. While in small retail shops education did not seem to play any major role in deciding the nature of tasks, in big retail there is a formal hierarchy of tasks. If the worker had the aptitude and had completed $12^{\text {th }}$ standard, she was usually considered for a post in the billing section.

All the Fair Price Shop workers were recruited through the Employment Exchange. But elsewhere education did not translate into a formal process of recruitment based on qualifications in the private retail stores. There, workers approached stores in their locality where 'Wanted' signs had been posted; or 
were referred to job openings by friends informed about work by their employers. Only two workers in private retail, both in large supermarkets, reported some form of formal recruitment process. One had responded to a hand bill advertising an opening, followed by a short interview, while the other had to attend a short interview at the head office. The overwhelmingly informal means of recruitment meant that most workers had no idea about regulations regarding confirmation of employment, probation, termination, etc. Workers in the bigger stores merely had to submit photocopies of their ration cards and/or $10^{\text {th }} / 12^{\text {th }}$ class school certificates as proof of age.

\section{Employment}

There was significant difference in the size of the labour forces in the different categories of stores. The large supermarkets employed over a hundred workers. Two of the supermarkets, Large-A and Large-B employed 162 workers (40\% women) and 150 workers respectively. By contrast, the medium size stores employed around ten workers. Both Medium-N and Medium-O employed 10 workers each (all women). The small stores either did not have any employees (confining operations to family labour) or had just one supplementary employee.

\section{Work conditions}

\section{Wages and other legally mandated economic benefits:}

Our research questions concerned the relationship of workers' pay to the minimum wage and the extent to which both tasks and pay were differentiated across the categories of gender and of store scale. 


\section{$\underline{\text { Wages }}$}

The legally-defined minimum wage under the law for retail workers in Tamil Nadu is Rs. 3655 per month. Table1 gives details of wages of workers and normal working hours.

Table1: Wages work experience and working hours, 2012-13

\begin{tabular}{|l|c|c|c|c|c|}
\hline $\begin{array}{c}\text { Enterprise } \\
\text { type }\end{array}$ & Sample & Hours & Average & Average & Experience \\
\hline & number & work & wage & hourly wage & (years) \\
\hline & & (hrs/day) & (Rs/month) & (Rs) & \\
\hline & & & & & \\
\hline Supermarket & 10 & 9.9 & 5080 & 20 & 1.1 \\
\hline Medium & 9 & 11.6 & 5322 & 18 & 2.0 \\
\hline Small/wholesale & 14 & 13.1 & 6571 & 19 & 3.2 \\
\hline PDS & 4 & 8.0 & 10750 & 72 & 14.7 \\
\hline
\end{tabular}

Source: Field survey, 2012-13

Average wages were lowest in the supermarkets. Of the ten workers in the sample employed in big supermarkets, only one male worker employed in a large supermarket (in the billing section, with two and a half years' experience, and a wage of Rs.7500 per month) and one woman worker in another large supermarket (a team leader, with two and a half years' experience, and a wage of Rs.7500 per month) had a wage of more than Rs.5000 per month. Another (male) worker in a large supermarket with one and a half years work experience was paid Rs.5000 per month. Four more workers employed in that supermarket for less than a year received wages of Rs.4600. While workers knew that they were entitled to incentives every month, they could not quantify the amount, or the basis on which such incentives would be paid.

Workers employed in the medium-sized local super-markets received a higher average wage. Only one worker, the oldest aged 56 years, was paid a wage less than Rs.5000 per month. 
Surprisingly to us, workers employed in small retail and wholesale stores were paid the highest wages among the categories of retail stores. One reason for this seeming anomaly in wage levels might be a gender bias prevalent in wage determination. All workers in the small stores were male workers, while workers employed in the supermarkets in the sample were women. Another reason might be the reward for experience. Wages were higher for the small store workers in the sample as they had worked for longer in retail. However, in fact there does not seem to be any strong relationship between experience and wages. There is a small positive correlation between experience and wage in the sample (excluding the four employed in the Fair Price Shops who were atypical) although it is important to note that the range of wages paid does not exceed a ratio of 1:2.

Table2: Wages and experience on job

\begin{tabular}{|l|c|c|c|}
\hline Experience & & Wages & \\
\hline (years) & & $($ Rs/month) & \\
\hline & $<\mathbf{5 0 0 0}$ & $\mathbf{5 0 0 0 - 7 5 0 0}$ & $>\mathbf{7 5 0 0}$ \\
\hline & & & \\
\hline$<1$ year & 6 & 3 & 1 \\
\hline $1-3$ years & 1 & 12 & 1 \\
\hline$>3$ years & 1 & 3 & 5 \\
\hline
\end{tabular}

Source: Field survey, 2012-13

Table 2 presents the distribution of wages by the experience of workers. The median wage in the retail sector is in the range of Rs.5000-7500 per month. The sample data also indicates the starting wage as being less than Rs.5000 per month, wages moving up to the range of Rs. 5000-7500 with 1-3 years' experience. Only workers with more than three years' experience can earn more than Rs.7500 per month in wages. This compares favourably with the garment sector, where wages in Chennai for skilled women workers (tailors) are in the range of Rs.3500-4000 per month.

\section{$\underline{\text { Bonus }}$}


The payment of a bonus is not only a customary practice, it is defined by clear legal provisions. However in small retail the bonus is an arbitrary concession while the legal provisions are rarely implemented in the large stores.

Only two workers among the big supermarket employees knew they were eligible for a bonus. One of them, the sole male worker in the category, with two and a half years' experience said that he was eligible for a month's wage as a bonus. Four from the medium size stores said that they received a bonus payment. However the bonus payment was much lower than even one month gross wages, which has been the customary norm and is the legal allowance. Eight of the 14 workers in the small stores category claimed that they were paid a bonus during the festival season. The bonus amount ranged from Rs.3000 to Rs.7000. ${ }^{18}$ So the large scale enterprises currently offer less recognition to workers by means of this practice than do small family firms.

\section{Social security:}

All workers in registered firms should be entitled to social security. In practice only one worker among the ten in the sample of large sized firms (with two and a half years work experience) said that she had Employees State Insurance (ESI) and Provident Fund (PF) entitlements. She had a letter of appointment that clearly indicated the break-up of wages and entitlements, (which included ESI and PF). In addition, the letter also specified eligibility to "Gratuity, Leave, Paid Holidays, etc., as applicable under relevant provisions and the rules of the company in force from (sic)". But there was no detailing of these provisions, or of eligibility conditions. Another worker claimed that she would be eligible for PF and ESI after a year's employment. All the other workers were unaware of

\footnotetext{
${ }^{18}$ With male workers employed in small retail in the sample, while the variation in annual bonus payments cannot be ascribed to gender discrimination its arbitrariness is a characteristic of wage work in the informal sector.
} 
these entitlements. Their low awareness of their entitlements may also have been the product of lack of experience in employment and lack of membership in a union.

Workers employed in the local medium size stores showed greater awareness of their rights and entitlements. Six out of the nine in the sample said that PF deductions were being made/would be made. Even so they did not know the percentage being deducted from their wages for PF and ESI, nor did any have PF numbers and ESI identity cards let alone any knowledge of their eligibility for gratuities.

Among the small retail stores, none of the workers were eligible for PF or ESI benefits since the stores fall below the threshold of number of employees that make it mandatory for employers to make social security contributions. ${ }^{19}$ Nine of the workers said that they would receive a "settlement" amount when they left employment. This could be seen as a form of gratuity payment. However, there seemed to be no fixed criterion for calculating such a settlement amount. This too is at the employer's discretion. Six workers said that normally the shop owner covered medical expenses. Four explained that sums of the order of Rs.200-500 were given to them to take care of medical expenditure when the need arose.

Two employees in the Fair Price Shops with 27 years and 28 years work experience were eligible for annual bonuses of $8.33 \%+1.67 \%$ ex gratia (totalling 10\%) and a small pension after retirement. However, a third worker who had joined only three years previously said that she had been paid a bonus the previous year of Rs.2000 (her gross wage was Rs.7000 pm); while the fourth, with one year experience said that she did not receive a bonus for her previous year.

\footnotetext{
${ }^{19} \mathrm{PF}$ and ESI coverage are mandatory in all establishments employing 20 or more workers.
} 
While social security rights are imperfectly and arbitrarily claimable, their parody in the informal labour arrangements of small stores is more a matter of personalised loyalty and customary practice than of rights.

\section{Other non-monetary benefits:}

Here too, arbitrary benefits in kind determine levels of effective social protection and raise the wage in small stores - with cash and kind benefits handed out by employers for a worker's needs. With the formalisation of capital these benefits are disappearing and only in a minority of cases being replaced by workers' rights.

There was no in-kind payment in the big and medium retail stores. Only three workers said they got snacks two days a working week.

By contrast, nine workers in the small retail stores were provided food and accommodation by the employer. Among these, in the case of two married and older workers, their accommodation rent was paid by the employer. One worker who earned only Rs.5000 per month after 17 years of experience at the same store justified the low wages in terms of the owner of the store's providing food and accommodation for him and his wife. (His wife worked as a domestic in the house of the owner, and also did domestic work in other neighbouring houses.)

In two of the small stores, workers worked half days on Sundays (in addition to working the remaining six days of the week) and received Rs.100 as a special Sunday payment. Five workers said that the shop owner gave them a set of clothes every year in the absence of uniforms in small stores, and two more said that they would be taken on a short tourist trip - in most cases to religious places - along with the employer's family each year. In small retail the 
discretionary, arbitrary and personalised nature of employment practices persists.

\section{Employment relation, intensity of work, supervision and surveillance:}

Legislation on work and workplace regulation clearly sets out working hours and rest breaks for all forms of employment and employer types including, where it is used, practices for shift work.

\section{Hours of work and over-time ${ }^{20}$}

The retail sector is distinguished by very long hours of work. Except in the government-run Fair Price Shops, in all other sampled retail establishments, the hours of work were in excess of 8 per day. The average working hours increased progressively from 10.3 hours in the large supermarkets through 11.6 hours in the medium size local supermarkets to 13.1 hours for the small stores (see Table3). The average hourly wage equalised across all establishments at Rs.18-20. While some workers in the sample (in one medium sized store and five small stores) worked through weekends/part weekends, they were also separately compensated for this extra work. Hence we have assumed a common denominator of 26 for the number of working days in a month.

Table3: Adjusted hourly wage

\begin{tabular}{|c|c|c|c|c|c|}
\hline $\begin{array}{c}\text { Enterprise } \\
\text { type }\end{array}$ & Hours & OT hours & Average & Average & \begin{tabular}{c} 
Adjusted \\
\hline
\end{tabular} \\
& work & $\begin{array}{c}(\mathbf{8} \mathbf{~ h r} \\
\text { basis })\end{array}$ & wage & hourly wage & $\begin{array}{c}\text { hourly } \\
\text { wage*21 }\end{array}$ \\
\hline & (hrs/day) & & (Rs/month) & (Rs) & (Rs) \\
\hline
\end{tabular}

\footnotetext{
${ }^{20}$ The Tamil Nadu Shops and Establishments Act 1947 clearly prescribes that a worker shall normally work 8 hours a day, and 48 hours a week. Further the worker may be asked to work overtime, but the number of working hours including overtime should not exceed 10 hours in a day, and 54 hours in a week. Overtime work shall further be compensated at twice the normal wage. The Act is mandatory in all establishments employing twenty workers or more.

${ }^{21}$ The adjusted hourly wage has been calculated assuming that work beyond 8 hours is compensated at twice the hourly wage.
} 


\begin{tabular}{|l|c|c|c|c|c|}
\hline & & & & & \\
\hline Supermarket & 9.9 & 1.9 & 5080 & 20 & 17 \\
\hline Medium & 11.6 & 3.6 & 5322 & 18 & 13 \\
\hline Small/wholesale & 13.1 & 5.1 & 6571 & 19 & 14 \\
\hline PDS & 8.0 & 0.0 & 10750 & 52 & 52 \\
\hline
\end{tabular}

Source: Field survey, 2012-13

The law requires establishments to pay workers overtime (OT) at double the normal wage rate for work done beyond 8 hours per day. If we take into account the overtime hours to be calculated at a double rate, the adjusted hourly wage rate falls further, with the wage rate being slightly higher in the case of the large supermarkets. The Minimum Wage Act for Tamil Nadu, for Shops and Establishments gave the statutory minimum Wage for the period April 1, 2013 to March 312014 as Rs.160.76 per day. This is around Rs.20 per hour. For the period April 1, 2012 to March 31, 2013, when the survey was conducted, the Minimum Wage was Rs.140.57 per day, or Rs.17.57 per hour. We see from Table3 that the nominal average hourly wage for workers in all categories of employment, from small to large stores, was more than the prevailing minimum wage. However, when we take into account the adjusted hourly wage, all categories of employment were effectively in breach of the Act. The Tamil Nadu Shops and Establishments Act is restricted to shops employing twenty or more workers. Strictly speaking, regulation under the Act may be enforceable only in the large corporate supermarkets.

The wages were much higher in the Fair Price Shops, where the regulation of the 8-hour day is also strictly implemented.

\section{$\underline{\text { Work shift details }}$}

Three of the large supermarkets have a two shift system while a fourth in the sample has a three shift system. Workers reported having a say in which shift 
they are employed, and usually stuck to that shift throughout their employment in the store.

Table 4: Shift details for large and medium retail outlets

\begin{tabular}{|l|l|l|}
\hline Large-A & $\begin{array}{l}7.30 \mathrm{am}- \\
5.30 \mathrm{pm} \\
9 \mathrm{am}-8 \mathrm{pm}\end{array}$ & $\begin{array}{l}\text { One hour } \\
\text { break }\end{array}$ \\
\hline Large-B & $\begin{array}{l}7.30 \mathrm{am}-6 \mathrm{pm} \\
9 \mathrm{am}-7.30 \mathrm{pm} \\
11 \mathrm{am}-8.30 \mathrm{pm}\end{array}$ & $\begin{array}{l}\text { Half hour } \\
\text { break }\end{array}$ \\
\hline Large-C & $\begin{array}{l}9 \mathrm{am}-8 \mathrm{pm} \\
11 \mathrm{am}-8 \mathrm{pm}\end{array}$ & $\begin{array}{l}\text { 2 hours } \\
\text { break }\end{array}$ \\
\hline Large-D & $\begin{array}{l}9 \mathrm{am}-6 \mathrm{pm}, \\
12 \mathrm{noon}-9 \mathrm{pm}\end{array}$ & $\begin{array}{l}\text { One hour } \\
\text { break }\end{array}$ \\
\hline Medium-M & $9 \mathrm{am}-9.00 \mathrm{pm}$ & $\begin{array}{l}\text { Half hour } \\
\text { break }\end{array}$ \\
\hline Medium-N & $9 \mathrm{am}-9.00 \mathrm{pm}$ & $\begin{array}{l}\text { One hour } \\
\text { break }\end{array}$ \\
\hline $\begin{array}{l}\text { Medium-O (departmental } \\
\text { store) }\end{array}$ & $\begin{array}{l}9.00 \mathrm{am}- \\
8.30 \mathrm{pm}\end{array}$ & $\begin{array}{l}\text { 45 minutes } \\
\text { break }\end{array}$ \\
\hline
\end{tabular}

Source: Field survey, 2012-13

A time card punching system exists in three of the large supermarkets (Large-A, Large-B and Large-D) and and one medium store (Medium-M) for time of reporting to duty and leaving the establishment, and to keep track of the break times.In the other retail stores workers were expressly told of the timings for reporting to work and taking breaks. Through general enquiry and observation we found that in Large-A, generally workers in the second shift worked even until 10pm, far beyond the 8 PM closing time. Men generally worked in the first shift because stock needed to be unloaded in the morning.

In case of small retail and wholesale stores almost all the workers mentioned that they worked very long hours. The PDS workers worked 8 hours per day, but had staggered work shifts (8.30 AM to $12.30 \mathrm{PM} ; 3 \mathrm{PM}$ to $7 \mathrm{PM}$ ). One of them mentioned that due to the shortage of staff often she does not always have time for her lunch breaks. After finishing her work for the morning at 12.30 PM, another cycled each afternoon without compensation to deposit the daily sales proceeds with another larger PDS shop. 


\section{Leave $^{22}$}

Twenty seven of the 37 workers in the sample got a weekly day off. In the case of large and medium size stores, with the exception of 5 workers employed at Ponnu supermarket, all workers got a weekly day off. The five workers in Ponnu supermarket had only 3 Tuesdays off in a month. In the small retail and wholesale shops, nine of the 14 got a weekly day off while the remaining five worked half a day on Sundays.

Only five of the workers employed in the big and medium retail stores reported access to some form of paid leave or sick leave. All the workers in the small stores said that time off for vacation could be taken with the permission of the store owner and salary was generally not deducted. Again there was no norm on the length of time off each worker got. Six of the small store workers said that the owner had promised 10-15 days paid leave for the worker's marriage.

\section{$\underline{\text { Toilet/ breaks }}$}

Eleven workers in the big and medium retail stores said that they could use the toilet or restroom for 20 minutes during the day but had to inform the supervisor or manager before they did so. The others said that there was no restriction on toilet breaks. In the case of small retail stores three workers said that 30 minutes could be taken during the course of the day. The others said that there was more or less no restriction.

So it looks as though workers have less freedom for their own personal needs in the larger enterprises.

\footnotetext{
${ }^{22}$ The leave regulations under the Tamil Nadu Shops and Establishments Act 1947 allow a worker 12 days of earned leave after each completed year of work. In addition it allows the worker a maximum of 12 days sick leave and 12 days casual leave each year.
} 


\section{$\underline{\text { Supervision and surveillance }}$}

All the workers in the big retail stores were very aware of the presence of surveillance cameras. This constant watch affects their actions and the work atmosphere. Workers in Large-A, Large-B, Large-D and Medium-M reported surveillance cameras in their stores. In some cases, women workers reported that they were afraid to sit or talk to one another because of the high levels of surveillance. This was in stark contrast to the small retail stores where no such monitoring mechanism existed and there seemed to be more freedom and flexibility.

Fifteen respondents in the sample said talking to the supervisor or the shop owner was the only way by which problems at work could be solved. The presence of surveillance cameras clearly makes any form of collective action difficult, and workers have little choice but to seek an individual resolution to their problems with management. In small retail stores, six workers also said that they would sometimes approach the wife of the owner if problems arose.

Some workers in the big and medium stores reported supervisors being very "strict", and "shouting" at workers for making mistakes. However, most of them said that there was not much harassment at the workplace from supervisors. In Medium-N, the workers said that the supervisors were not bad, but the lady manager/ owner could be quite abusive.

\section{$\underline{\text { Work intensity and health }}$}

About half the workers interviewed specifically mentioned that in the normal course of their working day, the work involved some form of strenuous activity. In the case of the small retail and wholesale shops, strenuous activity included workers who were engaged in home deliveries and had to cycle long distances 
to deliver orders. In the case of big retail chains, six workers said that standing for long periods of time was difficult and caused leg or back pain. Two workers mentioned dust allergies in the storage area because of poor storage conditions. The heavy work unloading sacks delivered from the miller/ wholesaler was mainly handled by contract workers who accompanied the delivery, though male workers were also sometimes required to 'lend a hand'. It is evident that retail work is not light in terms of energy expenditure and that occupationrelated accidents and health conditions are far from rare.

\section{Improving work conditions}

Nine of the 14 workers currently employed in small retail or wholesale stores (all men) said that their only reason for working was to gain experience and save money. They would improve their economic status by opening a new store themselves. The cases of the women who worked in larger stores were different -eight workers saying that they would report to the manager or owner if they wanted to improve their work conditions, while some also said that to do this they would either look for another job, or continue their studies after saving some money.

It seems that to improve their conditions most workers take an exit option.

\section{Wages and expenditure:}

Employment in retail at low wages can be assumed only to be viable for families with more than one wage earner, where the wage earned would supplement existing family earnings. This is often the logic used to justify low wages in sectors predominantly employing women. However, in the sample we find this strongly refuted. 


\section{Wage adequacy}

Although only four of the 37 workers interviewed were the sole wage earners for their families (all of them being older male workers living with their spouses),fourteen workers contributed more than $50 \%$ of the total family expenditure while eight workers contributed around one-third of the total family expenditure. ${ }^{23}$ Twenty one workers said that they were able to 'save money at the end of the month'. Yet there was also a significant incidence of indebtedness: 17 workers among those employed in the large, medium and small private stores (nearly 50 percent of the sample) had debts against them, ranging from Rs.2,000 to Rs.200,000. So some both save and simultaneously incur debt. ${ }^{24}$

This evidence calls to question the argument that women's employment is a secondary supplement to male incomes and hence that wages in sectors employing primarily women can be kept low.

\section{$\underline{\text { Migrants }}$}

Nine of the 10 migrants in the sample, eight of them working in small stores (displaced to Chennai from other districts in Tamil Nadu), remitted money home. Most of them were from Tuticorin, Thirunelveli and Kovilpatti. Seven remitted more than half of their monthly earning to support their families at home.

\footnotetext{
${ }^{23}$ This is again in line with the reported experience of garment workers in Chennai as discussed with activists of the Garment and Fashion Workers Union.

${ }^{24}$ C.f. Guerin,I, S. Morvant and M. Villareal (eds) (forthcoming), Microfinance, debt and overindebtedness. Juggling with money. (OUP New Delhi)
} 
All the migrant workers (some living with their families - and some with spouses also working) were able to save some money. Six were able to save Rs.1,000 - Rs.3,000 from their monthly earnings. This is of significance as eight of the migrant workers worked in small stores. The workers in the small shops said that they did not consider this employment to be temporary, in contrast with many workers in the medium and large stores. The savings rate also shows how these workers were able to save a substantial proportion of their monthly wage (average monthly wage in small stores was Rs.6,571), indicating a significant level of non-cash support allowing wage workers to maintain their high savings rates.

\section{Discussion}

Here the implications of our analysis of the field material for labour prospects and politics are set out.

First, at the retail stage of the supply chains, the field study revealed an increase in the reach of formal regulation with the scale of ownership - from small stores to large retailers. The significantly lower hours of work in the large retail chain indicate a greater concern for the regulation of work in corporate retail. However, even in the large retail chains, the hours of work are still longer than the 8-hour day and no overtime is paid. The workers interviewed for this research have not been informed about the law pertaining to the working-day, including the 8-hour day norm and the requirement for overtime regulation and compensation.

Second, wages (average wages) decline counter-intuitively from the small store through the medium size store to large supermarkets. We have explained this partly as due to longer hours of work in the small stores, with the hourly wage being roughly the same across the sample (excluding the Fair Price Shops). But it may also be because women in big retail have the least work experience. The 
wage divide may also reflect a gender-segmented labour market - with men paid higher wages for the same or similar work. However, these explanations do not seem adequate. Part of the reason is likely to be that employment in small stores mobilises kinship relations or ties of locality. The worker in the small store is related to the owner by relationships of family, kinship, friendship and/or old village ties. The employer pays for trust and loyalty. In some instances the worker is treated as family, with board and lodging, and medical expenses paid - in a parody of occupation-based social security. The worker in the small store is therefore willing to stay with the job for longer periods of time. Yet another reason is that, from their job descriptions, workers in the small shops are given much higher levels of responsibility, including managing the shop on their own when the owner is not around. The higher wage would also be a return for the worker's handling much higher responsibility, and the owner having to retain the trust of the worker.

The statutory Minimum Wage in Tamil Nadu (notification wef April 1, 2012) for Shops and Commercial Establishments is Rs.140.57 per day, or Rs.3,654.82 for a 26 working-day month. This is a very low wage. However this assumes an 8-hr work day. If we take up employment in the large retail sector with average hours of work as 10.3, the overtime wages for 2.3 hours overtime work should be Rs.80.65, giving a legally minimum wage of Rs.241 per day, or Rs.6,226 per month for 26 working days. We similarly compute, for the average hours of work of 11.6 in the medium size stores, the legal minimum wage as being Rs.6,922; and for 13.1 hours in the small, store as Rs.8,290. Taking into account the 8-hr norm and double overtime payment, across the sample private retail employers are paying wages below the legal minimum wage.

The interview with a woman worker from Large-B raised some significant issues. She had a letter of appointment dating from sometime in 2010, which 
defined her wage component: a basic wage (basic + DA) of Rs.1,500 per month, and a total wage in hand of Rs.4,594. With the social security component, the wage worked out to Rs.5,000 per month in 2010.

Table10a: Basic Wage based on Appointment Letter

\begin{tabular}{|l|r|}
\hline & (Rs/month) \\
\hline Wage components & 1500 \\
\hline Basic + DA & 750 \\
\hline House rent allowance & 1544 \\
\hline Consolidate allowance & 800 \\
\hline Conveyance allowance & 4594 \\
\hline Total &
\end{tabular}

Source: evidence from survey 2012-13

Table 10b: Wage + Employers Contribution to Social Security Benefit

\begin{tabular}{|l|r|}
\hline Total cost to company & \\
\hline Company contribution to & 180 \\
PF & \\
\hline Company contribution to & 8 \\
EDLI & 218 \\
\hline Company contribution to & $\mathbf{5 0 0 0}$ \\
ESIC & \\
\hline Cost to company & \\
\hline
\end{tabular}

Source: as above

We find from the survey that newly recruited employees in the same company Large-B in late 2012 claimed a similar entry wage of around Rs.4,500-4,600 per month. This means that over a period of two years the entry level wage had remained static - despite the fact that the wage includes an inflation indexed component in the form of Dearness Allowance. The indexed portion of the wage is less than a third of the total pay. At best it provides limited protection against inflation. In addition to the fact that entry level pay has remained the same, the period has been one of extremely high inflation, especially food price inflation, so the employer benefits from a persistent reduction in the real wage. Further, the company is contributing to the PF fund at $12 \%$ of the basic wage (basic + DA), whereas, legally the company is bound to pay PF on the gross 
wage. The company's practice is illegal. Lack of trade union organisation in the sector prevents these problems of regulation and illegality from being taken up. Interestingly, a senior manager with the parent company of Large-B said that as wages were low, there was a high turnover of employees among workers in the large retail supermarkets. This mirrors the situation in the garments sector in Chennai, where high labour turnover is endemic.

The normal range for the entry-level wage is around Rs.4,000-5,000 per month in the big retail firms in the sample. From the three cases of experienced workers, with a year's experience the wage increases to around Rs.5,000 per month, and with two years' experience the worker obtains around Rs.7,500 per month. A real wage increase therefore happens only after the worker has remained in one company for two years.

Third, it is useful to compare wages and work conditions in retail with those in the garment sector, given that employment in big and medium retail is from the same pool of workers as in garments. Wages in retail are higher than in garments, where the statutory minimum wage for a tailor is Rs.3,632 per month. However the hours of work are longer in retail, even allowing that unpaid overtime work is prevalent in the garment sector. The advantage of retail seems to be that supervision is more humane, despite the use of video cameras in large stores. Some workers in the sample mentioned that there are less rushed periods when they are able to sit down and rest their feet. This is in contrast with the garments sector where workers are faced with a constant, relentless work pressure.

Fourth, this field-research raises questions about the impact of modernisation of the retail trade. Will modernisation introduce better wages and working conditions? Does it lead to more women being employed in retail - and if so, what impact will this have upon regulation in the industry? The sample's gender 
distribution indicates a progressive feminisation of the workforce with the modernisation and increase in scale of the retail trade. There is thus a risk that, as in the case of other sectors employing predominantly women, the retail sector will have to deal with issues of sexual harassment at the workplace, and physical safety for women, who often have to work late hours, up to 8 and 9 in the night.

In 2012-3, there is little sign of the formal regulation of work in most of the retail sector, which continues to be informally organised. This lack of formal regulation of employment relations, and existing low wages in the sector will affect the regulation of work and wages in the newly growing formal sector in retail. We should also take into account that the provisions of the PF and ESI Acts, and the Tamil Nadu Shops and Establishments Act are mandatory only for establishments employing twenty workers or more. This clearly would leave out of the ambit of most regulation all the small retail stores, and most medium size stores. In our sample it is only the large supermarkets that would attract the provisions of these regulations.

Given the pull-down effect in wages and regulation of informal retail on the formal sector there is likely to be no pressure on them from either employees or the government to adopt better practices. In our field research, the comprehensiveness of compliance with regulation and the hourly wage both increase as economic activity moves from informal to formal sector, but the wage band remains very small.

In the absence of any political interest, and with labour departments' having scant resources, the state regulation of the Labour Laws is extremely poor, except where workers are themselves organised. Our field evidence demonstrates that most workers, even in the corporate retail sector, have no knowledge of their legal rights of employment. There is also practically no 
organisation of workers in this sector, to represent them and negotiate their work problems.

Finally, the study poses some interesting suggestions about the manner in which large supermarket chains might affect the organisation of rice and other staples retail in the country. In terms of size, the large supermarket dwarfs the medium and small stores. One supermarket can replace over a hundred small stores. However, when analysed only in terms of rice sales, we see that the displacement effect is much smaller. The average supermarket rice sales equal the rice sale from say 3-4 medium stores, or 20 small stores. The small and medium stores also render a service that the large supermarket would not be able to substitute. For one instance, many small stores allow credit purchases to their steady customers, which is vital for their clientele.For another instance, one medium sized store (Medium-O) sourced its rice from a particular mill in Arani (distance around $115 \mathrm{kms}$ from Chennai) as against the practice of most other stores sourcing rice from Red Hills (around $10 \mathrm{kms}$ distance). The store owner explained that the rice mill still used traditional sun-drying methods, as against mechanical drying processes in mills in Red Hills. The rice from the traditional drying was informally 'branded' as superior, and he had a specialised clientele for this 'brand'. These shards of evidence are suggestive of social segmentation in rice retailing of a sort that may serve to protect the economy of small stores. 